rotation. If any tutors would like a copy would they please contact my secretary, Mrs Sue Knott.

The Royal London Hospital

I. O. AZUONYE

(St Clement's)

2a Bow Road

London E3 $4 L L$

\section{Careers in rehabilitation psychiatry}

\section{DEAR SIRS}

The paper on Careers in Rehabilitation Psychiatry (Psychiatric Bulletin. November 1990, 14, 665-667) covered the training requirements, job structure and potential frustration. Scrutiny of the forms filled in by College Representatives on Advisory Appointment Committees on Rehabilitation Consultant posts in England and Wales shows that there were 17 completely new national advertisements for consultant rehabilitation jobs in 1988, 21 in 1989 and 18 to 30 September 1990 (56 posts in all). Thirty-five appointment committees were held during this time, 26 rehabilitation jobs were filled, nine posts were not filled at the appointment committee stage.

Many health districts in England and Wales have advertised for a rehabilitation consultant but have been unsuccessful in appointing. Some health authorities persisted; for example, three posts were filled one year after the first advertisement. Unsuccessful health authorities may often alter the job or change local consultant responsibilites to assume rehabilitation commitments.

The Social, Community and Rehabilitation Section guidelines indicate special responsibility for rehabilitation should take five sessions and district services should be run on the basis of one rehabilitation session per 30,000 population. The recent audit of appointments shows that the sessional commitment for new consultants varied between two and ten.

There has been a considerable increase in the establishment of senior registrar posts in both general adult psychiatry and old age psychiatry (Psychiatric Bulletin, November 1990, 14, 696). Rehabilitation psychiatry senior registrar posts are not specifically designated.

There are 18 rehabilitation consultants recognised as trainers of senior registrars in England and Wales (compared with six in 1984). These one year slots are not filled regularly, however, because senior registrar rotational schemes have more training places than higher professional trainees. In addition those taking the option may have no intention of becoming rehabilitation consultants.

A survey of consultant psychiatrists assessing career choice and appropriateness of training (Psychiatric Bulletin, January 1984, 8, 2-5) revealed that the majority rated their training in rehabilitation as unsatisfactory.

Our audit of appointments shows that only 15 out of the 27 successful applicants fulfilled the criteria for rehabilitation experience promoted by the College. Seven senior registrars were appointed without appropriate training and a further five were appointed proleptically. Only a quarter of those interviewed had adequate recognised rehabilitation training.

The Department of Health has agreed that each region in England and Wales should have at least one rehabilitation consultant and that person should be recognised as a senior registrar trainer. With at least 20 consultant rehabilitation posts being advertised per year supply is not keeping up with demand. We suggest that each region should have at least two senior registrar training posts, until the present short fall is corrected and rehabilitation services for people with long term mental illness are more uniformally established.

\section{Coney Hill Hospital}

Gloucester GL4 $7 Q^{J}$

Bryan ANSTeE

Chairman of Social, Community and

DOUglas Fowlie

Rehabilitation Section

\section{Patients participation in examinations in psychiatry}

DEAR SIRS

In response to the correspondence by Dr Lynch (Psychiatric Bulletin, May 1990, 14, 308), the American Board of Psychiatry and Neurology currently organises three oral examinations in general psychiatry and one oral examination in child and adolescent psychiatry per year. Approximately 1,500 patient examinations are conducted in general psychiatry and 180 in child and adolescent psychiatry.

To our knowledge, there has never been a study similar to that conducted by Drs Persaud and Meux (Psychiatric Bulletin, February 1990, 14, 65-71).

However, there is much anecdotal information that is obtained in the course of the examinations and following these examinations. It is our impression that there is not a similar level of morbidity and relapse following the examination experience. This may, in part, result from different methods and criteria for patient selection. For the American Board of Psychiatry and Neurology oral examinations, patients are not exclusively recruited from in-patient services and, indeed, many are out-patients as well as day care patients and, hence, the potential for decompensation following the examination may be less likely. Also, the examination is a one-half hour examination with the patient and the candidate in the room with two examiners at all times and a third 